\title{
Editorial
}

\section{A letter to our readers}

In this issue of Diabetologia you will find a new set of "Instructions to Authors". Some of you may regard these regulations as somewhat pedantic, but we feel strongly that the old instructions had to be up-dated and that our editorial policies needed to be clearly laid out. In fact, during the discussions between the editorial team and our authors over the presentation of manuscripts, it often became quite obvious that more specific guidelines would be useful. Altogether, these Instructions are meant to assist authors during the preparation of manuscripts and to facilitate the editorial process. We spent a great deal of time and effort in putting together these new "Instructions to Authors", and we sincerely hope that they will meet with the approval of our readers and authors and welcome their suggestions for improvement. A complete set of the "Instructions to Authors" will be printed in Diabetologia biannually at the beginning of each volume, and a summary of the most important points in every issue of the journal. Now that the new Instructions have been formally introduced, we will have to return manuscripts to authors who do not comply with these instructions. We have unfortunately had to increase the rules and regulations somewhat because the increase in the number of manuscripts we are receiving (up 25\% in 1983) is forcing us to streamline and formalize our procedures to some extent. Thus, an improvement in the formal presentation of manuscripts might also help to decrease the publication time of manuscripts printed in Diabetologia even further, an all-too-elusive goal which we will continue to pursue.

The new "Instructions to Authors" require that each manuscript submitted be accompanied by a letter signed by all of the authors stating that the article represents an original paper which has not been published before and is not being considered for publication elsewhere. During the past 18 months, there have been various regrettable incidents which appear to make the necessity of such a statement unavoidable. A number of unfortunate developments in academic medicine have recently led to the equally unfortunate tendencies to in- crease the number of co-authors and decrease the substance of papers by breaking up studies into several articles or, even worse, by publishing them simultaneously or consecutively in several journals. There has been quite a bit of - sometimes amusing - speculation on why we need so many co-authors for most of our scientific papers [1]. Sometimes it almost looks as if the cooperation of many colleagues is required to cut a nice and well-rounded study into many minute articles and communications which are then submitted to different journals, very often with different individuals serving as first authors. Actually, there is very little justification for this abuse of our publication system, unless the basic intention is to enlarge the publication list of as many colleagues as possible. On the other hand, it facilitates the foundation and well-being of new journals. This seems to be of particular relevance in the field of diabetology, where we are confronted with an ever-growing number of scientific and practically-oriented journals surfacing everywhere in whatever languages and formats. Many of these new organs are exclusively and primarily based on commercial rather than scientific or medical motivations on the part of either the publisher or the pharmaceutical company running the particular journal directly or indirectly through advertising. Whereas some of the new journals are a welcome addition to the diabetological literature, others clearly are not. In any case, the rising number of diabetes journals may increase the temptation to split articles up into two or more for submission to different publishers. Also, it may erode the peer review system, since the pool of willing and competent referees that editors can rely upon is certainly limited.

A particular problem in this context is the increasing frequency of double and repeat publication, both attempted and realized, and the possibilities of preventing this [2]. The Editorial Board of Diabetologia has been confronted with more than half-a-dozen discovered cases of flagrant attempts at double publication during the past year. In our efforts to control this growing practice, we have established contacts with the Editors-in- 
Chief of the leading international diabetes journals (Diabetes, Diabète et Metabolisme and Diabetes Care) in order to work out practical means for preventing multiple publication of data. Furthermore, the Vancouver group of editors of medical journals has formulated a statement of policy on multiple publication [3]. This statement defines the subtle difference between repetitive publication and parallel publication. Repetitive publication cannot be accepted in Diabetologia under any circumstances, a rule which applies even if the report was published (or submitted) in a monograph or in the proceedings of a symposium, etc. (In fact, the citation of articles from such publications and conference proceedings should be kept at an absolute minimum, since these papers have usually not been peer-reviewed and in many instances appear in volumes not readily available.) A number of sanctions have been suggested against authors who have been caught during or after an attempt to publish the same data several times. These include the refusal to consider the publication of their manuscripts for a number of years after the incident [4], a measure which was discussed but not adopted at the 1983 Meeting of the Editorial Board of Diabetologia. More practical ways to react might include publishing an editorial statement, such as the one suggested by the Editor of the British Medical Journal [2], in cases where the repeat publication is discovered only after it has appeared. With reference to the term parallel publication (also called "dual language" publication), Diabetologia will not consider manuscripts which have already been published in a national journal or a monograph, symposium proceedings, etc., even if the primary publication is openly disclosed. On the other hand, the Editorial Board and the publisher of Diabetologia, who holds the copyright to articles appearing in our journal, will be pleased to consider requests to reproduce in other journals, with proper acknowledgement, English or translated versions of papers that have been published in Diabetologia.

Apart from the prevention of double publications, the request for the statement to be signed by all authors of a paper submitted to Diabetologia is also meant to serve another purpose. We have had several cases in the past year in which papers already under review had to be withdrawn because one or more of the co-authors were not aware of and did not agree with their submission for publication; there was even a case where the senior author had never been shown the paper and discovered his co-authorship quite by accident. This has occasioned unnecessary work for our already overburdened reviewers and editorial staff. More important, we feel that the responsibility of being a co-author should be acknowledged in writing. Obviously, there are various standards for justifying co-authorship of a scientific paper, and these standards may differ substantially from country to country. The crucial condition, however, seems to be that the co-author accepts the scientific responsibility and identifies his or her contribution to the content of the article submitted for publication, as we have all realized in the wake of the Darsee affair $[5,6]$.

Finally, I would like to say that I have enjoyed my first eighteen months as the Editor of our journal. The plague of complaints and telephone calls from disappointed Authors has sometimes been discouraging but still not as terrible as anticipated [7], and there have been many unawaited rewards in the help and loyalty of friends both old and new. And so, armed with its new "Instructions to Authors", the Editorial Team of Diabetologia enters the twentieth year of the journal's existence in good spirits.

Düsseldorf, 1 July 1984

Michael Berger

\section{References}

1. Anonymous (1983) Who should be an author? Br Med J 287: $1569-1570$

2. Anonymous (1984) Repetitive publication: a waste that must stop. Br Med J 288: 661-662

3. International Committee of Medical Journal Editors (1984) Multiple publication. Br Med J 288: 52

4. Abelson PH (1982) Excessive zeal to publish. Science 218: 954

5. Kastor JA (1984) Authorship and the Darsee case. Int J Cardiol 5: 7-11

6. Short EM (1983) L'Affair Darsee. Clin Res 31:448-449

7. Nattrass M, Tattersall RB, Alberti KGMM (1983) To a new editorin-chief. Diabetologia 24:307 